SPECIAL REPORT

\title{
SPIRITUAL INTELLIGENCE TRAINING FOR PSYCHOSOCIAL REHABILITATION
}

\begin{abstract}
The Spiritual Intelligence training program has evidenced as a contemporary intervention in mental health to bring psychological well-being by increasing spiritual quotient and inner strength. Spiritual intelligence $(S Q)$ is a novel concept in psychology and needs to be distinguished from IQ and $E Q$ as it uses spiritual skills and abilities to solve rational problems, to create awareness, enrich meaning and purpose of life. Spiritual intelligence is the ability of a person to possess a socially relevant virtues in life by understanding 'self' and having a high degree of morality, compassion and commitment to human values. It is one-month training program consisting of eight separate group sessions. It aims to develop spiritual intelligence through seven steps journey. Spiritual intelligence training worked with the help of four essential components: existential thinking, personal meaning, transcendental awareness and consciousness. It was first introduced by Bowell in 2005. Although spiritual intelligence training is being used around the world, it is still unidentified by many professionals in Pakistan. Spiritual intelligence training can be implemented widely in universities, hospitals, rehabilitation centers, and in business organizations to promote individual growth, life satisfaction and self-identity. Spiritual intelligence has been determined as a predictor of adaptive coping strategies hence, proved as an essential concept in rehabilitation of various psychological pathologies and to improve social participation. Spiritual intelligence is an innovative approach to clinical and educational research, providing an opportunity to study it as a clinical intervention in future. More research studies are required to establish its cultural efficacy and applicability.
\end{abstract}

\section{KEYWORDS}

Emotional intelligence, Rehabilitation, Mental Health, quality of life, life satisfaction, emotions.

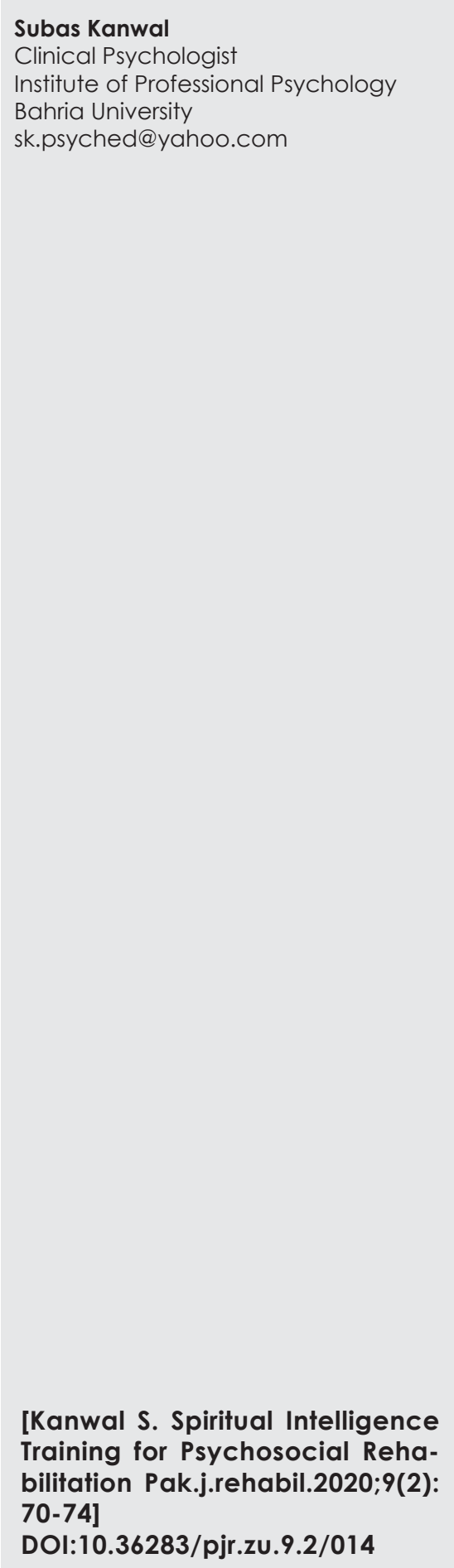

Subas Kanwal

Institute of Professional Psychology

Bahria University

sk.psyched@yahoo.com

[Kanwal S. Spiritual Intelligence Training for Psychosocial Reha70-74]

DOI:10.36283/pjr.zu.9.2/014 


\section{NTRODUCTION}

\section{Spiritual Intelligence}

Spirituality is considered as the fourth dimension of human health by the resolution WHA37 passed in the 37th World Health Assembly in 1984, making the spiritual dimension core element in all health planning strategies for the member states. Following which health definition updated as "A complete balance of physical, mental, social, and spiritual wellbeing and not merely an absence of disease and infirmity".

The health and wellbeing is achieved by balance between physical, psychosocial and spiritual aspects. It is facilitated by four skills. First, making one enable to function and execute what one's desires in socially acceptable manner. Second is self-regulating, third, is mental and physical condition of happiness and finally nonexistence of pain (Mishra \& Kamla, 2014) ${ }^{2}$. The inclusion of spirituality domain in Health definition has raised studies to understand how spirituality is associated with psychological wellbeing. The increase of psychological research in this domain highlights the significance of spirituality in relation with an individual's physical, emotional, as well as psychological health.

Spiritual intelligence can be described as a set of mental abilities that play an important role to create awareness, unique integration, and adaptive use of the nonmaterial and transcendent dimensions of one's existence that results in deep existential reflection, enrichment of meaning, realization of a transcendent self, and mastery of spiritual skills ${ }^{3}$.

\section{Difference between $I Q, E Q$ and $S Q$ :}

In the beginning of the $20^{\text {th }}$ century, mental health researches on spiritual intelligence accelerated. Aristotle's meaning of man as "a rational creature" is expanded and included in intelligence quotient (I.Q). It refers to the ability of an individual to think rationally, solve problems and apply ones learning in different life situations, while Emotional Intelligence is defined as ability of an individual to recognize and manage ones and others emotions. It is a necessary skill for adaptive functioning. Spiritual intelligence is the ability of a person to possess a socially relevant virtues in life by understanding 'self' and having a high degree of morality, compassion and commitment to human values ${ }^{4}$.

\section{Components of Spiritual Intelligence}

King in 2008 described four major components of spiritual intelligence: (1) critical existential thinking, (2) personal meaning production, (3) transcendental awareness, and (4) conscious state expansion. The first component of spiritual intelligence is defined as critical existential thinking, as the tendency to critically anticipate the nature of existence, reality, space, universe, time, death, and other existential or metaphysical issues. Personal meaning production is the second component, which is defined as the ability to derive personal meaning and goal in all substantial and mental experiences, including the capability to create and master a life purpose. Transcendental awareness, third component of spiritual intelligence is defined as the capacity to recognize transcendent aspects of the self (e.g., a transpersonal or transcendent self), of others, and of the physical world (e.g., non-materialism, holism) during the normal, waking state of consciousness, along with ability to identify their relationship to one's self and to the substantial elements. The final component of spiritual intelligence is conscious state expansion, described as the ability to move in and move out higher/spiritual states of consciousness at one's own discretion (as in deep contemplation, meditation, prayer, etc.) ${ }^{3}$

\section{Spiritual intelligence training}

Spiritual intelligence training now serves as an intervention in mental health on the way to advance psychological wellbeing as well as spiritual abilities. Studies conducted in this regards are useful for instructors, professional counselors, business personnel's, and doctors to promote growth and well-being in their clients. Bowell known as founder of Spiritual Intelligence Training, discussed about the improvement of the inner strength and spiritual intelligence of a person, and suggests to discover the "why" of what we do, rather than the "what" or "how".

The seven steps of Spiritual Intelligence given proposed by Bowell will lead to overall psychological wellbeing of a person, which are awareness, meaning, evaluation, being centered, vision, projection and mission. Awareness: It is the first step towards spiritual intelligence. Sense organs play a vital role in developing awareness. It increases recognition, associations, memories and dialogues. The main purpose of this step is to make an individual capable to become aware and understand the abstract meaning. The spiritually intelligent person would avoid from the relaxed position and keep oneself awaken to bigger challenges and adventures of evolving life. Meaning: This step emphasized on value of judgments in one's life. It grows consciousness of the world and all that lives within it. The meaning of things cannot be assumed, it is gained through experience. Evaluation: It is a procedure by which one understands her/his self and other person too. One should not do evaluation from the identity level of 'self' alone. Being centered: Being centered is to attain a higher level of engagement overall. This step makes an individual dedicated to the growth of 'self' as a meaningful life. Vision: Seeing what others have not yet seen is an indication of visionary. One should have a vision 
that can see beyond the physical world. This step helps in developing consciousness about the situation. Projection: Action is followed by projection. Projection starts in the management of 'self', and in the vision of great wealth that can be achieved, when one actually sees the truth of the situation. Mission: This final step towards spiritual intelligence incorporates one's self with the truth of the situation. Mission statement is an important aspect of the corporate identity and it inspires those who follow ${ }^{5}$.

\section{Spiritual intelligence and mental health of Pakistani youth}

Pakistan population comprised of more young people. $64 \%$ of total population is under 30 and $29 \%$ lies in age bracket 15 to 29 year's old'6. The majority youth are students living with an extremely exigent demanding and difficult life. Individuals, who position among small or middle earnings social group, have less number of opportunities to development their full potentials. Social adversities such as unemployment, poverty and increase in inflation rates impacts overall health of an individual. Mental health issues in Pakistan have increased rapidly in last two decades. Depression and anxiety is found to be highest among mental health issues in Pakistan. Substance use disorder is another prevailing problem in Pakistan. Around 6.7 million people suffer from substance use disorder majority of who does not avail mental health services due to society taboo and lack of awareness. It further makes them vulnerable to further mental health issues ${ }^{6}$. Also a very less social support for engagement and facilitation of emotional wellbeing is available.

Psychological wellbeing of young adults depends essentially on the connection between the spiritual believes and environment. Recent evidences suggest that spiritual intelligence has strong positive association with mental well-being and reason in life so that an increase in spiritual intelligence shields the individual from negative impact of social adversities.

A study conducted in 2017 on youth from Rawalpindi and Islamabad reveled that participants with high emotional intelligence presented stronger self-identity and good mental health7, similarly in an another study spiritual intelligence was found to enhance work-life balance ${ }^{8}$ thus it can be concluded by spiritual intelligence can prove produce promising effects in reducing mental health issues in youth of Pakistan.

\section{Spiritual intelligence training in academic and job setting}

Spiritual interventions are extensively used in educational settings meant for diverse reasons. Recent researches showed self-efficiency, quality of life and self-responsibility can be increase in students through spiritual intelligence training?. It has also proved that spiritual intelligence training improves management practices of teachers and motivates them through vision, boost their creativity. Further, research has proved significant increase in job satisfaction of employees through spiritual intelligence training and education. There is a strong connection among the spiritual intelligence as well as adjustment amongst the college students. The result of Correlation analysis concluded that there is a momentous relationship was found between optimistic thinking and spiritual intelligence in students. Spirituality also has a strong link with quality of life in academic students?.

A research was conducted in Pakistan, by Awan and Sitwat in 2014, to explore the relationship between workplace spirituality and psychological wellbeing and to investigate the predictors of psychological well-being in mental health professionals. The results of the study revealed significant positive association of workplace spirituality and self-esteem and psychological well-being in mental health professionals. Self-esteem and workplace spirituality were found to be predictors of psychological wellbeing ${ }^{10}$.

Spiritual intelligence training in rehabilitation setting One of the studies revealed that following spinal cord injury, the patient experience a high level of spiritual distress which is found to be associated with depression and pain. The study highlighted that addressing spiritual wellbeing can improve rehabilitation of spinal cord injured patient by enhancing self-awareness and hope"1.

In rehabilitation centers and hospitals, patients interact with nurses most of the time. According to recent studies, there is a positive significant correlation between nurses' spiritual intelligence and their clinical competency. Because of the positive effects of spiritual intelligence on nurses' clinical competency and quality of care, it is recommended to develop nurses' spiritual intelligence during their education and by way of continuous medical education ${ }^{12}$.

Researches have determined the relationship between spiritual intelligence and the resiliency of rehabilitation staff of the affiliated rehabilitation centers of Tehran and Shemiranat rehabilitation administrations in 2016-2017. Rehabilitation staff is resilient to some types of stress based on their working conditions, and spiritual intelligence and resiliency are two important factors which can directly have an effect on job stress and accordingly on the staff's quality of life, and indirectly on patients' care. It was showed that staff with higher spiritual intelligence had a greater resilience score. Spiritual intelligence training would be helpful for all professional staff in different disciplines, including pastoral/spiritual care providers, psychologists, physi- 
cians, nurses, and social workers, to enhance their spiritual intelligence. Based on research conducted in this field, some suggested ways to develop spiritual intelligence are to spend some time reflecting on your purpose in life; to pay attention to the differences between your attitude and others' worldviews; and to make a commitment to spiritual growth ${ }^{13}$.

Nursing staff are the one of the most important healthcare professional. Their high energy demanding job and work nature make them vulnerable to compassion fatigue. Another research conducted in Main University Hospital of QOM, Iran showed a significant positive relationship between Spiritual Intelligence (SI) and job performance among nurses. In light of these researches, it is recommended to include Sensory intelligence training courses into in-service training for nurses and other healthcare workers ${ }^{14}$.

Spiritual Intelligence leads to changes in attitudes, behaviors, and patient support among nurses. Promotion of SI can help to improve nurses' mental health status thereby improving patient's safety and organizational efficiency.

Spiritual training is not only effective for health care providers, also for people suffering from, serious diseases such as cancer. Recent studies show that spiritual training improves psychological wellbeing and adjustment with the situation, and it also supports family to deal with emotional ${ }^{15-16}$.

\section{DISCUSSION}

Recent studies highlight positive association of spiritual intelligence with wellbeing. Qualitative analysis of research data shows that after receiving spiritual intelligence training participants feel more satisfied spiritually connected to their inner self. It enables a person to identify and channelize their negative emotions. It provides an opportunity of self-growth and improvement in personality. (Ramachandaran, 2017).

Individual with high spiritual intelligence possess relevant purpose in life, also they have high level of compassion and commitments to human values. It reflects thoughtful subjugation of self and connection to community, expressed through compassionate actions in daily life, and contributes to psychological wellbeing and healthy human development. Spiritual intelligence highlights many forms of understanding and incorporating the mind and spirit into in the daily life. It can be cultivated by questioning, research and practice. Owing to it impactful benefits, it reflects high rehab potential not only for those suffering from mental health disorders, also for people experiencing severe physical health conditions however, limited work has be done on finding cultural relevancy of spiritu- al training thus more research and careful studies are required to identify the efficacy of spiritual intelligence training in Pakistani culture.

\section{CONCLUSION}

Studies have explored the literature, application and outcome of spiritual intelligence training program as an intervention to increase psychological wellbeing. Statistical outcome showed an effective application of spiritual intelligence intervention as an organized training program to increase well-being, life satisfaction, quality of life and other variables.

\section{REFRENCES}

[1] Dhar N, Chaturvedi SK, Nandan D. Spiritual health, the fourth dimension: a public health perspective. WHO South-East Asia J. Public Health. 2013;2(1):3.

[2] Mishra PR, Vashist KA. A review study of spiritual intelligence, stress and well-being of adolescents in 21 st century. International Journal of Research in Applied Natural and Social Sciences. 2014; 2(4):11-24.

[3] Skrzypińska K. Does spiritual intelligence (SI) exist? A theoretical investigation of a tool useful for finding the meaning of life. JORH 2020:1-7.

[4] Mahmood A, Arshad MA, Ahmed A, Akhtar S, Rafique Z. Establishing linkages between intelligence, emotional and spiritual quotient on employees performance in government sector of Pakistan. Mediterr. J. Soc. Sci. 2015;6(6 S2):553-.

[5] Bowell RA. The seven steps of spiritual intelligence: The practical pursuit of purpose, success, and happiness. Nicholas Brealey Publishing; 2004.

[6] (ATLAS of Substance Use Disorders Resources for the Prevention and Treatment of Substance Use Disorders (SUD) Country Profile: PAKISTAN, 2020).

[7] Cisheng W, Shah MS, Jamala B, Aqeel M, Ahmed A, Gul M. The Moderating Role of Spiritual Intelligence on the relationship between Emotional Intelligence and Identity Development in Adolescents. Foundation University J. Psychol 2017;1 (1):77-107.Safa

[8] Chaleshtari K, Sharifi T, Ghasemi Pirbalooti M. A Study of the Effectiveness of Group Spiritual Intelligence Training on Self-Efficacy and Social Responsibility of Secondary School Girls in Shahrekord. Social Behavior Research \& Health. 2017; 1 (2):81-90.

[9] Ilyas N, Arshad T. Spiritual Intelligence, Work-Family Conflict and Psychological Distress among University Teachers.BJPP. 2017;16(1).

[10] Safa Chaleshtari K, Sharifi T, Ghasemi Pirbalooti M. A Study of the Effectiveness of Group Spiritual Intelligence Training on Self-Efficacy 
and Social Responsibility of Secondary School Girls in Shahrekord. Social Behavior Research \& Health. 2017 1 (2):81-90.

[11] Awan S, Sitwat A. Workplace spirituality, self-esteem, and psychological well-being among mental health professionals. Pakistan J Psychol. 2014:125-49.

[12] Siddall PJ, Mclndoe L, Austin P, Wrigley PJ. The impact of pain on spiritual well-being in people with a spinal cord injury. Spinal Cord. 2017;55(1):105-11.

[13] K Karimi-Moonaghi H, Gazerani A, Vaghee S, Gholami H, Salehmoghaddam AR, Gharibnavaz R. Relation between spiritual intelligence and clinical competency of nurses in Iran. Iran J Nurs Midwifery Res $2015 ; 20(6): 665$.

[14] Ebrahimi Barmi B, Hosseini M, Abdi K, Bakhshi E, Shirozhan S. The Relationship between Spiritual
Intelligence and Resiliency of Rehabilitation Staff. J Pastoral Care Counsel. 2019;73(4):205-10.

[15] Khandan M, Eyni Z, Koohpaei A. Relationship between spiritual intelligence and job performance: A case study of nurses and nursing aids in the main university hospital of Qom, Iran. Health, Spirituality and Medical Ethics. 2017;4(3):8-13.

[16] Moazedyan P, Bagheri $M$. The spiritual intelligence training to family, affective, social and Physical adjustments in breast cancer patients. J. Appl. Rehabil. Couns. $2016 ; 6(1): 89-101.0$

[17 Rezavandi S, Masoumpoor A, Farahani AS, Nasiri M. The Relationship between Spiritual Intelligence and Depression in Parents of Children with Cancer. J. Biochem. Technol. 2018;9(3):45. 